Annals of Plant Sciences

ISSN: 2287-688X

OPEN ACCESS

Research Article

www.annalsofplantsciences.com

\title{
Characterization of genetic diversity of wild pomegranate collected from Himachal Pradesh, India.
}

Ritu Mahajan*, Azhar Javed and Nisha Kapoor

School of Biotechnology, University of Jammu, Jammu, J \& K, India.

Received: 1/12/2018; Revised: 1/21/2018; Accepted: 1/30/2018

\begin{abstract}
Wild pomegranate is distributed in three states of India. However, genomic information is rare in this plant. In this paper we studied the genetic diversity of wild pomegranate collected from different places of Himachal Pradesh using RAPD primers. A high degree of polymorphism of $80.7 \%$ was observed. Cluster analysis demarcated the accessions into two distinct groups. The genetic dissimilarity index calculated varied from 0.16 to 0.68 for twentyone wild pomegranate genotypes. The presence of high genetic diversity can be useful for understanding the process of domestication and cultivated pomegranate breeding programs.
\end{abstract}

Keywords: wild pomegranate, genetic diversity, molecular markers, characterization

\section{Introduction}

Wild pomegranate (Punica granatum L.), is well adapted to a wide range of climatic conditions and therefore has a wide geographical distribution. In India, wild pomegranate grows in Western Himalayan regions that include states of Jammu and Kashmir, Himachal Pradesh and Uttarakhand (Mishra et al., 2016). Dried arils of wild pomegranate or Daru are used in preparation of anardana, a rich source of vitamin $\mathrm{C}$ and vitamin $\mathrm{B} 5$. The edible part of pomegranate is rich in anthocyanins and hydrolysable tannins (Wu and Tian, 2017). Most of the wild cultivars being grown locally are farmers' selection and are being maintained by vegetative propagation Because of these medicinal properties the wild pomegranate germplasm in Himalayan region is eroding fast due to human incursion (Rana et al., 2012; Khan et al., 2014).

Since, the wild pomegranate has originated in response to large number of environmental stresses so exploiting its ex situ conserved genetic diversity is vital to overcome future problems which will be associated with narrowness of genetic base of modern cultivars. Studies on genetic diversity of wild pomegranate can illustrate the various facets of the domestication process and reasons for its diversification ( Langlie et al., 2014).

Despite its potential, genetic studies and genomic resources in this plant species are almost lacking. Molecular methods if created could substantially help in formulating breeding strategies for genetic improvement of wild pomegranate. Therefore, the present study focuses on collecting wild pomegranate germplasm from HP and studying diversity in the germplasm at molecular level.

\section{${ }^{*}$ Corresponding Author:}

Dr. Ritu Mahajan,

Assistant Professor, School of Biotechnology,

University of Jammu, Jammu, (J \& K), India.

E-mail: ritufeb@gmail.com

\section{Materials and Methods}

Plant material

Twenty-one leaf samples of wild pomegranate were collected from different places of Himachal Pradesh (H.P) (Table 1) and were brought to laboratory in pre- sterilized polythene bags. They were washed and stored at $-80^{\circ} \mathrm{C}$ till further use.

Table 1. Plant collection sites and their respective codes

\begin{tabular}{ccc}
\hline S. No. & Collection site & Code No. \\
\hline 1 & Nahan & N1 \\
2 & Naina Tikker & N2 \\
3 & Naina Tikker & N3 \\
4 & Naina Tikker & N4 \\
5 & Naina Tikker & N5 \\
6 & Nauni & N6 \\
7 & Mandi & M7 \\
8 & Mandi & M8 \\
9 & Kullu & K9 \\
10 & Kullu & K10 \\
11 & Joginder nagar & J11 \\
12 & Palampur & P12 \\
13 & Dharlaghat & D13 \\
14 & Dharlaghat & D14 \\
15 & Dharlaghat & D15 \\
16 & Solan & S16 \\
17 & Solan & S17 \\
18 & Palampur & P18 \\
19 & Kangra & K19 \\
20 & Kangra & K20 \\
21 & Rajgarh & R21 \\
\hline
\end{tabular}

Molecular analysis

DNA isolation and quantification: The genomic DNA was isolated from each collected wild pomegranate accession using CTAB method (Saghai-Maroof et al., 1984). Since wild pomegranate is rich in polyphenols so $1 \%$ PVP was added to improve the quantity and concentration of DNA. The DNA was finally suspended in TE $(10 \mathrm{~mm}$ Tris $\mathrm{HCl}$ and $1 \mathrm{mM}$ EDTA, pH 8.0) buffer and quantified by UV spectrophotometer and also on 
$0.8 \%(\mathrm{w} / \mathrm{v})$ agarose gel. The DNA was stored at $20^{\circ} \mathrm{C}$ till further use.

PCR amplification using RAPD primers: In vitro DNA amplification was performed in $0.2 \mathrm{ml}$ PCR tubes using 50-75ng of genomic DNA of each accession in a final volume of $25 \mu \mathrm{l}$ reaction mixture. A total of forty different RAPD primers (Promega) were used for analysis (Table 2). The PCR reaction mixture contained $5.0 \mu \mathrm{l}$ template DNA, $12.2 \mu \mathrm{L}$ ddH2O, $2.5 \mu \mathrm{l}$ 10X PCR buffer, $3.5 \mu \mathrm{l}$ of $100 \mathrm{mM}$ dNTPs, $1.5 \mu \mathrm{l}$ of $5 \mu \mathrm{M}$ primer and $0.3 \mu \mathrm{L}$ Taq polymerase $(5 \mathrm{U} / \mu \mathrm{l})$. The amplification reactions were carried out using a Thermal Cycler (Bio-rad) which was programmed to include initial denaturation at $94^{\circ} \mathrm{C}$ for $4 \mathrm{~min}$, followed by 40 cycles of denaturation at $94^{\circ} \mathrm{C}$ for $1 \mathrm{~min}$, annealing at $35^{\circ} \mathrm{C}$ for $1 \mathrm{~min}$ and primer extension at $72{ }^{\circ} \mathrm{C}$ for $1.5 \mathrm{~min}$. The final extension cycle was of $7 \mathrm{~min}$ at $72^{\circ} \mathrm{C}$.

Agarose Gel electrophoresis: The PCR products were resolved on $1.2 \%$ agarose gel in $0.5 \mathrm{X}$ Trisacetate-EDTA (TAE) buffer with $1 \mathrm{~kb}$ ladder (Fermentas) so as to determine the size of the amplified bands. Ethidium bromide was added at concentration of $0.5 \mu \mathrm{g} / \mu \mathrm{l}$ to the gel. The gel was run at $5 \mathrm{~V} / \mathrm{cm}$ for $1-2$ hour and then visualized under Gel Documentation System. The gels were photographed and the pictures were stored for further analysis.

Data collection and diversity analysis: The bands representing particular alleles in RAPD gels were scored manually and only clear bands were considered as monomorphic and polymorphic bands. The dissimilarity matrix based on the unweighted neighbor-joining method, was used for the clustering of genotypes and the analysis was performed using DARWin 5.0 (http://darwin.cirad.fr), (Perrier et al., 2003). The genetic dissimilarity was calculated for all the twenty-one genotypes of wild pomegranate. Confidence limits of different clades were tested by bootstrapping 500 times to assess the repetitiveness of genotype clustering (Felsenstein, 1985).

\section{Results and Discussion}

Molecular analysis

A total of forty RAPD primers were used to unknot the genetic diversity in the twenty-one collected wild pomegranate genotypes (Table 1). The gels were scored on the basis of presence or absence of bands in the form of binary data ( 0 for absence and 1 for the presence of band). The genetic dissimilarity from the matrix of binary data was calculated using Dice index of similarity (Dice, 1945). From a total of tested forty RAPD primers, thirty-three RAPD primers were polymorphic while seven primer showed monomorphic character. By analyzing the gels manually, a total of 192 bands were amplified in twenty-one wild pomegranate genotypes. Out of 192 bands, 165 bands were polymorphic and 27 bands were monomorphic. The overall polymorphism level was $80.7 \%$ (Table 2). The number of bands produced by each RAPD primer ranged from 1 (PGCT073, PGCT111, PGCT112) to 12 (PGCT062). A $100 \%$ polymorphism was obtained with maximum primers, while few primers exhibited incoherent percentage of polymorphism, like PGTCO55 and PGCTO 85 showed $71.42 \%$ and $50 \%$ polymorphism respectively. The observed pattern of polymorphism in wild pomegranate genotypes revealed significant amount of diversity in wild pomegranates that grow in HP. Nazary et al., (2009) observed very high level polymorphism of $97.08 \%$ in forty-nine wild pomegranate genotypes collected from Himachal Pradesh and Uttarakhand suggesting that the Western Himalayan region is significantly diverse. Ranade et al., (2009) studied genetic diversity in cultivated and wild pomegranate and observed a high level of genetic diversity present amongst the wild genotypes. Pitsiouni et al., (2012) discriminated different pomegranate genotypes using RAPD and ISSRs and observed high genetic similarity upto $95 \%$ between the samples collected from the agricultural area of Pella, and the samples collected from the Institute of Pomology of Naoussa. They suggested that these genotypes might be clones of some cultivars.

The genetic dissimilarity index calculated varied from 0.16 to 0.68 for 21 wild pomegranate genotypes (Table 3). Maximum genetic distance calculated from Diversity matrix $(0.68)$ was between the genotypes K10 and R21, collected from Kullu region and Rajgarh in Sirmaur district respectively. Both the places are geographically isolated by a distance of $265 \mathrm{Kms}$ apart. The genotypes N2 and N3 (0.13, from Naina Tikker) ; M7 and M8 (0.17, from Mandi region); $\mathrm{K} 9$ and $\mathrm{K} 10$ ( 0.16 , from Kullu region) showed very less genetic dissimilarity as the genotypes were collected from same places so were not very diverse. This variation in dissimilarity coefficient range also supports the presence of genetic diversity in wild pomegranates. Also, Ericisli et al., (2011) observed an average genetic similarity of 0.32 among the genotypes collected from Coruh Valley, Turkey which clearly indicates significant genetic diversity among the genotypes. 
Table 2. List of polymorphic primers and the degree of polymorphism in twenty-one wild pomegranate genotypes

\begin{tabular}{|c|c|c|c|c|}
\hline S.No & Primer & $\begin{array}{c}\text { Number of } \\
\text { amplified bands }\end{array}$ & $\begin{array}{c}\text { Number of } \\
\text { polymorphic bands }\end{array}$ & \% Polymorphism \\
\hline 1 & PGCT109 & 9 & 9 & 100 \\
\hline 2 & PGCT093A & 8 & 8 & 100 \\
\hline 3 & PGCT093B & 4 & 4 & 100 \\
\hline 4 & PGCT107A & 10 & 10 & 100 \\
\hline 5 & PGCT062 & 12 & 12 & 100 \\
\hline 6 & PGCT083 & 6 & 6 & 100.0 \\
\hline 7 & PGCT055 & 7 & 5 & 71.4 \\
\hline 8 & PGCT095 & 6 & 6 & 100.0 \\
\hline 9 & PGCT088A & 4 & 4 & 100.0 \\
\hline 10 & PGCT032A & 7 & 7 & 100.0 \\
\hline 11 & PGCT017A & 4 & 2 & 50.0 \\
\hline 12 & PGCT103 & 10 & 10 & 100.0 \\
\hline 13 & PGCT107B & 8 & 8 & 100.0 \\
\hline 14 & PGCT099 & 4 & 4 & 100.0 \\
\hline 15 & PGCT085 & 5 & 5 & 100.0 \\
\hline 16 & PGCT017B & 9 & 8 & 88.8 \\
\hline 17 & PGCT 104 & 7 & 6 & 85.7 \\
\hline 18 & PGCT 088B & 5 & 3 & 60.0 \\
\hline 19 & PGCT111 & 2 & 1 & 50.0 \\
\hline 20 & PGCT032B & 5 & 5 & 100.0 \\
\hline 21 & PGCT109 & 5 & 5 & 100.0 \\
\hline 22 & PGCT055 & 4 & 3 & 75.0 \\
\hline 23 & PGCT061 & 5 & 3 & 60.0 \\
\hline 24 & PGCT093 & 7 & 5 & 71.4 \\
\hline 25 & PGCT087 & 5 & 3 & 75.0 \\
\hline 26 & PGCT110 & 3 & 3 & 100.0 \\
\hline 27 & PGCT037 & 6 & 2 & 33.3 \\
\hline 28 & PGCT028A & 4 & 2 & 50.0 \\
\hline 29 & PGCT083 & 4 & 3 & 75.0 \\
\hline 30 & PGCT057 & 8 & 7 & 87.5 \\
\hline 31 & PGCT112 & 3 & 1 & 33.3 \\
\hline 32 & PGCT073 & 3 & 1 & 33.3 \\
\hline 33 & PGCT028B & 6 & 4 & 66.6 \\
\hline Total & ------ & 195 & 165 & ----- \\
\hline Mean & ------- & 5.9 & 3.0 & 80.7 \\
\hline
\end{tabular}

\section{Cluster tree}

The partition in the UPGMA tree shows a clear genetic differentiation among wild pomegranate genotypes collected from different regions of HP (Fig 1). The generated dendrogram based on the dissimilarity matrix showed two distinct clusters:

1. Cluster I contains subclusters containing genotypes collected from Palampur, Kangra, Mandi, Joginder Nagar and Kullu region.

2. Cluster II has subclusters containing genotypes collected from Solan, Nauni, Rajgarh and Dharlaghat region.

The genotype N1 collected from Nahan is completely diverse from all other collected genotypes of wild pomegranate in the tree. This shows that this genotype is genetically distant from other genotypes and this could be due to the geographical isolation or the environmental conditions of the place. The variations or diversity present in the accession can also be attributed to the spontaneous mutations.

The genotypes K9 and K10 both collected form Kullu region closely resemble the genotype M7 collected from Mandi region as both the places are $30 \mathrm{kms}$ apart so less diverse. The genotypes P12 and P18, both collected form Palampur belong to different sub-clusters of cluster I. This could be due

to human intervention in the past or may be they are related to each other by descent (Narzary et al., 2009).

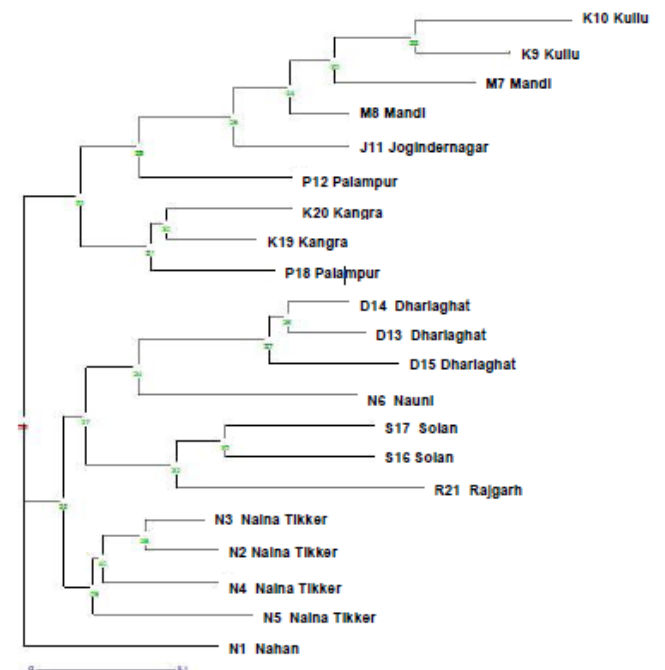

Fig 1: Dendrogram generated using UPGMA analysis, showing genetic relationships among twenty-one wild pomegranate genotypes based on RAPD data

The main cluster II has further formed three subclusters containing genotypes collected from the 
places Naina Tikker, Solan, Rajgarh, Nauni and Dharlaghat. These places are not much geographically isolated. The first sub-cluster of cluster II, has all the genotypes (N2, N3, N4, N5) collected from Naina Tikker from the Sirmaur district while genotype N1 collected from Nahan which is $37 \mathrm{KM}$ towards North from Naina Tikker does not belong to cluster II. This could be due to precise migration of wild plants from their center of origin or are descendents of isolated plants (Narzary et al., 2010). The presence of high genetic distances between the genotypes suggest that they may have originated from genetically divergent parents or have a long history of adaptation to their respective micro-climatic regions (Ericisli et al., 2011).

Table 3: Diversity matrix between 21 wild pomegranate accessions as revealed by RAPD Primers

\begin{tabular}{|c|c|c|c|c|c|c|c|c|c|c|c|c|c|c|c|c|c|c|c|c|}
\hline & N1 & N2 & N3 & N4 & N5 & N6 & M7 & M8 & K9 & K10 & J11 & P12 & D13 & D14 & D15 & S16 & S17 & P18 & K19 & K20 \\
\hline N2 & 0.29 & & & & & & & & & & & & & & & & & & & \\
\hline N3 & 0.28 & 0.13 & & & & & & & & & & & & & & & & & & \\
\hline N4 & 0.24 & 0.21 & 0.20 & & & & & & & & & & & & & & & & & \\
\hline N5 & 0.31 & 0.24 & 0.23 & 0.23 & & & & & & & & & & & & & & & & \\
\hline N6 & 0.41 & 0.33 & 0.32 & 0.33 & 0.30 & & & & & & & & & & & & & & & \\
\hline M7 & 0.52 & 0.45 & 0.43 & 0.44 & 0.41 & 0.45 & & & & & & & & & & & & & & \\
\hline M8 & 0.43 & 0.36 & 0.35 & 0.35 & 0.32 & 0.36 & 0.17 & & & & & & & & & & & & & \\
\hline K9 & 0.54 & 0.47 & 0.46 & 0.46 & 0.43 & 0.47 & 0.22 & 0.20 & & & & & & & & & & & & \\
\hline K10 & 0.59 & 0.52 & 0.50 & 0.51 & 0.48 & 0.52 & 0.27 & 0.25 & 0.18 & & & & & & & & & & & \\
\hline J11 & 0.43 & 0.36 & 0.35 & 0.35 & 0.32 & 0.36 & 0.25 & 0.16 & 0.27 & 0.32 & & & & & & & & & & \\
\hline P12 & 0.39 & 0.34 & 0.33 & 0.31 & 0.36 & 0.46 & 0.57 & 0.48 & 0.59 & 0.64 & 0.48 & & & & & & & & & \\
\hline D13 & 0.47 & 0.40 & 0.38 & 0.39 & 0.36 & 0.40 & 0.47 & 0.39 & 0.50 & 0.54 & 0.39 & 0.52 & & & & & & & & \\
\hline D14 & 0.39 & 0.31 & 0.30 & 0.30 & 0.28 & 0.32 & 0.39 & 0.30 & 0.41 & 0.46 & 0.30 & 0.44 & 0.20 & & & & & & & \\
\hline D15 & 0.43 & 0.35 & 0.34 & 0.34 & 0.32 & 0.36 & 0.43 & 0.34 & 0.45 & 0.50 & 0.34 & 0.48 & 0.24 & 0.16 & & & & & & \\
\hline S16 & 0.41 & 0.36 & 0.34 & 0.32 & 0.38 & 0.47 & 0.58 & 0.50 & 0.61 & 0.65 & 0.50 & 0.39 & 0.53 & 0.45 & 0.49 & & & & & \\
\hline S17 & 0.40 & 0.35 & 0.33 & 0.31 & 0.37 & 0.46 & 0.57 & 0.49 & 0.60 & 0.64 & 0.49 & 0.38 & 0.52 & 0.44 & 0.48 & 0.21 & & & & \\
\hline P18 & 0.38 & 0.33 & 0.31 & 0.29 & 0.35 & 0.44 & 0.55 & 0.47 & 0.58 & 0.62 & 0.46 & 0.20 & 0.50 & 0.42 & 0.46 & 0.37 & 0.36 & & & \\
\hline K19 & 0.37 & 0.32 & 0.31 & 0.29 & 0.34 & 0.43 & 0.54 & 0.46 & 0.57 & 0.62 & 0.46 & 0.24 & 0.49 & 0.41 & 0.45 & 0.36 & 0.35 & 0.18 & & \\
\hline K20 & 0.39 & 0.35 & 0.33 & 0.31 & 0.37 & 0.46 & 0.57 & 0.49 & 0.60 & 0.64 & 0.48 & 0.27 & 0.52 & 0.44 & 0.48 & 0.39 & 0.38 & 0.15 & 0.22 & \\
\hline R21 & 0.43 & 0.38 & 0.37 & 0.35 & 0.40 & 0.49 & 0.60 & 0.52 & 0.63 & 0.68 & 0.52 & 0.41 & 0.55 & 0.47 & 0.51 & 0.32 & 0.31 & 0.39 & 0.32 & 0.41 \\
\hline
\end{tabular}

\section{Conclusions}

The present study indicates that diversity exists within the wild pomegranate germplasm collected from the HP region. Since, a high amount of genetic diversity in the plants was observed which has further resulted in the easily adaptation of plants to different environmental conditions. Studies on the molecular analysis of different genotypes can further result in establishing phylogenetic relationship within the genotypes belonging to same or different places. This will further help in understanding the process of domestication in the near future.

\section{Acknowledgements}

The authors are thankful to DST, New Delhi for providing the financial support as major research project on wild pomegranate. The authors are also thankful to School of Biotechnology, University of Jammu for providing the basic facilities to carry out this research work.

\section{References}

1. Dice LR. Measures of the amount of ecologic association between species. Ecology, 26, (1945): 297-302.

2. Ercisli S, Gadze J, Agar G, Yildirim N, Hizarci Y. Genetic relationships among wild pomegranate (Punica granatum) genotypes from Coruh Valley in Turkey. Genetics and Molecular Research, 10, (2011): 459-464.
3. Felsenstein F. Confidence limits in phylogenies: an approach using bootstrap. Evolution 39 (1985): 783791.

4. Khan MA, Khan MA, Hussain M, Mujtaba G. Plant diversity and conservation status of Himalayan Region Poonch Valley Azad Kashmir (Pakistan). Pakistan Journal of Pharmaceutical Sciences, 27, (2014): 1215-39.

5. Langlie BAS, Mueller NG, Spengler RN, Fritz GJ. Agricultural origins from the ground up: Archaeological approaches to plant domestication. American Journal of Botany, 101, (2014): 1601-1617.

6. Mishra G, Sharma G, Taria SK, Lata S, Negi D. Determination of pollen viability of wild pomegranate accessions in the mid-hill zone of Himachal Pradesh International Journal of Farm Sciences, 6, (2016): 105-110.

7. Narzary D, Mahara KS, Rana TS, Ranade SA. Analysis of genetic diversity among wild pomegranates in Western Himalayas, using PCR methods. Scientia Horticulturae, 121, (2009): $237-$ 242.

8. Narzary D, Rana TS, Ranade SA. Genetic diversity in inter-simple sequence repeat profiles across natural populations of Indian pomegranate (Punica granatum L.). Plant Biol (Stuttg), 12, (2010): 806-813.

9. Perrier X, Flori A, Bonnot F. Genetic diversity of cultivated tropical plants. N: Enfield Science Publishers, Montpellier pp. 43-76, 2003. 
10. Pitsiouni M, Linos A. and Hagidimitriou M. Drogoudi P. Genetic Diversity of Greek Wild and Cultivated Pomegranate (Punica granatum L.) Genotypes and Cultivars Using Molecular Markers. Acta Hort, 940, (2012): 193-200

11. Rana JC, Dutta M and Rathi RS (2012) The wild pomegranate germplasm in Himalayan region is eroding. Indian Journal of Genetics and Plant Breeding, 72, (2012): 115-129.

12. Ranade SA, Rana TS, Narzary D. SPAR profiles and genetic diversity amongst pomegranate (Punica granatum L.) genotypes. Physiol Mol Biol Plants. 15, (2009):61-70.

13. Saghai-Maroof MA, Soliman KM, Jorgensen RA, Allard RW. Ribosomal DNAspacer-length polymorphism in barley: mendelian inheritance, chromosomal location, and population dynamics. Proceedings of the National Academy of Sciences, 81, (1984): 8014-8019.

14. Wu S, Tian L. Diverse Phytochemicals and Bioactivities in the Ancient Fruit and Modern Functional Food Pomegranate (Punica granatum). Molecules, 22, (2017): 1606.

\section{Cite this article as:}

Ritu Mahajan, Azhar Javed and Nisha Kapoor.

Characterization of genetic diversity of wild pomegranate collected from Himachal Pradesh. Annals of Plant Sciences 7.2 (2018) pp. 2042-2046.

do $\mathrm{http://dx.doi.org/10.21746/aps.2018.7.2.10}$

Source of support: DST, New Delhi, India. Conflict of interest: Nil 